\title{
Anatomical Demonstration of Ocular Dominance Columns in Striate Cortex of the Squirrel Monkey
}

\author{
Jonathan C. Horton and Davina R. Hocking \\ Beckman Vision Center, University of California at San Francisco, San Francisco, California 94143-0730
}

The squirrel monkey is the only primate reported to lack ocular dominance columns. Nothing anomalous about the visual capacity of squirrel monkeys has been found to explain their missing columns, leading to the suggestion that ocular dominance columns might be "an epiphenomenon, not serving any purpose" (Livingstone et al., 1995). Puzzled by the apparent lack of ocular dominance columns in squirrel monkeys, we made eye injections with transneuronal tracers in four normal squirrel monkeys. An irregular mosaic of columns, averaging $225 \mu \mathrm{m}$ in width, was found throughout striate cortex. They were double-labeled by placing wheat germ agglutininhorseradish peroxidase into the left eye and $\left[{ }^{3} \mathrm{H}\right]$ proline into the right eye. The tracers labeled opposite sets of interdigitating columns, proving they represent ocular dominance columns.
The columns were much clearer in layer IVc $\alpha$ (magno-receiving) than IVc $\beta$ (parvo-receiving). In the lateral geniculate body, the parvo laminae showed extensive mixing of ocular inputs, suggesting that increased label spillover contributes to the blurred columns in layer IVc $\beta$. The cytochrome oxidase (CO) patches were organized into distinct rows, but they bore no consistent relationship to the ocular dominance columns. These experiments indicate that ocular dominance columns are less well segregated in squirrel monkeys than macaques, but they are present. This fact is pertinent to a recent study reporting that ocular dominance columns are absent in normal squirrel monkeys, but induced to form by strabismus (Livingstone, 1996).

Key words: ocular dominance columns; squirrel monkey; striate cortex; cytochrome oxidase patches; strabismus; stereopsis
In layer IVc of striate cortex (primary visual cortex, V1), the afferents from the lateral geniculate body serving each eye are segregated into an elaborate mosaic of alternating inputs called ocular dominance columns (Hubel and Wiesel, 1965, 1969). Despite more than three decades of intensive research, the function of these columns has remained an enigma. The presence or absence of ocular dominance columns has been studied in a wide variety of species, searching for a clue to their role in visual processing. The data from this comparative anatomical approach are summarized in Table 1. It has been suggested that ocular dominance columns are part of the neural mechanism for stereoscopy (LeVay and Nelson, 1991). This notion is compatible with the grouping of species reflected in Table 1. In general, the species listed with ocular dominance columns are thought to have better stereovision than those without, although not all species have been tested.

The squirrel monkey is a conspicuous exception to the dichotomy reflected in Table 1 . It is the only primate reported to lack ocular dominance columns. Hubel et al. (1976) found no hint of ocular dominance columns in either hemisphere after injection of tritiated amino acids into one eye. Their absence was confirmed subsequently by numerous investigators with axon tracing methods and deoxyglucose autoradiography (Tigges et al., 1977; Hendrickson et al., 1978; Rowe et al., 1978; Hendrickson and Wilson,

\footnotetext{
Received April 22, 1996; revised May 30, 1996; accepted June 4, 1996.

This work was supported by grants from the National Eye Institute, That Man May See, and Research to Prevent Blindness. We thank the California Regional Primate Research Center, Davis, California, for help, especially David Robb and Jenny Short. The Primate Center is supported by National Institutes of Health Base Grant RR00169.

Correspondence should be addressed to Dr. Jonathan C. Horton, Beckman Vision Center, 10 Kirkham Street, University of California at San Francisco, San Francisco, CA 94143-0730.

Copyright (C) 1996 Society for Neuroscience $\quad 0270-6474 / 96 / 165510-13 \$ 05.00 / 0$
}

1979; Humphrey and Hendrickson, 1983; Tigges et al., 1984; Hendrickson and Tigges, 1985).

Recently, Livingstone et al. (1995) published the first data pertaining to stereoscopic depth perception in the squirrel monkey. They recorded robust evoked potentials to patterns generated by dynamic random-dot stereograms. From this finding, they concluded that the squirrel monkey can detect stereosopic depth, which "casts some doubt on the assumption that ocular dominance columns bear an important relation to stereopsis" (Livingstone et al., 1995).

In view of the findings by Livingstone and colleagues (1995), if ocular dominance columns are absent in squirrel monkeys, they obviously cannot be critical for stereovision. Although the weight of evidence cited above denying their existence seemed persuasive, anatomical methods have improved with the introduction of radioactive tracers of greater specific activity and the development of better techniques to flat-mount the visual cortex (Horton, 1984; Olavarria and Van Sluyters, 1985; Tootell and Silverman, 1985). For example, Murphy et al. (1995) recently have found a pattern of cytochrome oxidase (CO) staining in flat-mounted striate cortex of cats that was missed by previous observers (Wong-Riley, 1979; Horton and Hubel, 1981; Horton, 1984; Price, 1985). Their discovery illustrates the value of re-examining the cortex for subtle columnar patterns that might have eluded earlier efforts. Consequently, before consigning squirrel monkeys to the category of goats, rabbits, and other species bereft of ocular dominance columns, we decided to look again for ocular dominance columns in squirrel monkeys.

\section{MATERIALS AND METHODS}

Eye injection of tracer. These experiments were conducted in four unrelated male squirrel monkeys (Saimiri sciureus) from the California Regional Primate Research Center. Their vital statistics are provided in 
Table 1. Ocular dominance columns in striate cortex

Columns present

Macaque
(Hubel and Wiesel, 1969)
Human
(Hitchcock and Hickey, 1980)
(Horton and Hedley-Whyte, 1984)
Owl monkey
$\quad$ (Rowe et al., 1978)
(Diamond et al., 1985)
Marmoset
$\quad$ (DeBruyn and Casagrande, 1981)
(Spatz, 1989)
Green vervet
(Hendrickson et al., 1978)
Red monkey
$\quad$ (Hendrickson et al., 1978)
Baboon
(Hendrickson et al., 1978)
Spider monkey
(Florence et al., 1986)

\author{
Talapoin monkey \\ (Florence and Kaas, 1992) \\ Capuchin monkey \\ (Hess and Edwards, 1987) \\ (Rosa et al., 1988) \\ White-faced saki \\ (Florence and Kaas, 1992) \\ Chimpanzee \\ (Tigges and Tigges, 1979) \\ Cat \\ (Shatz and Wiesel, 1977) \\ Ferret \\ (Law et al., 1988) \\ Mink \\ (McConnell and LeVay, 1986) \\ Bushbaby \\ (Glendenning et al., 1976) \\ (Hubel and Wiesel, 1977) \\ (Diamond et al., 1985)
}

Columns absent

Rat

(Hubel and Wiesel, 1977)

Mouse

(Dräger, 1974)

Tree shrew

(Casagrande and Harting, 1975)

(Hubel, 1975)

Gray squirrel

(Weber et al., 1977)

Brushtailed possum

(Sanderson et al., 1980)

Rabbit

(Holländer and Hälbig, 1980)

Sheep

Goat

(Pettigrew et al., 1984)
Table 2. Before use, each animal received a complete neurovisual examination by a board-certified ophthalmologist (J.C.H.). The pupils, eye movements, eye alignment, ocular media, cycloplegic retinoscopy, and dilated fundi were normal. Specifically, no evidence for media opacity, abnormal or unequal refractive error, or strabismus was found in any animal.

Monkey 1 received an injection of wheat germ agglutinin-horseradish peroxidase (WGA-HRP) in the right eye to label the retino-thalamocortical projection by anterograde transneuronal transport (Itaya et al., 1984). The animal was anesthetized with ketamine $\mathrm{HCl}(10 \mathrm{mg} / \mathrm{kg}$, i.m.) and with one drop of topical $4 \%$ tetracaine $\mathrm{HCl}$. A drop of scopolamine $\mathrm{HBr} 0.25 \%$ was applied topically for mydriasis. The right eye was then massaged for several minutes to lower the intraocular pressure below 10 $\mathrm{mmHg}$. This procedure prevented reflux of tracer after injection into the eye. One milligram of WGA-HRP (Sigma, St. Louis, MO) dissolved in $20 \mu \mathrm{l}$ of balanced salt solution (Alcon Labs, Fort Worth, TX) was injected through the sclera $3.5 \mathrm{~mm}$ from the superotemporal limbus with a 29 gauge needle. The tracer was placed accurately into the mid-vitreous by putting a guard on the needle shank $7 \mathrm{~mm}$ from the tip and by watching the position of the needle in the eye with an indirect ophthalmoscope during injection. After tracer delivery, a retrobulbar injection of $1 \mathrm{mg}$ dexamethasone phosphate was made to minimize intraocular inflammation from the WGA-HRP. The animal was perfused $4 \mathrm{~d}$ later.

In monkeys 2, 3, and 4, the retino-thalamo-cortical projection was double-labeled by injecting $\left[{ }^{3} \mathrm{H}\right]$ proline into the right eye and WGA-HRP into the left eye. Two milliCurie of L- $\left[2,3,4,5-{ }^{3} \mathrm{H}\right]$ proline, specific activity 102-106 Ci/mmol (Amersham, Arlington Heights, IL), were dried under $\mathrm{N}_{2}$ gas, reconstituted in $20 \mu \mathrm{l}$ of balanced salt solution, and injected into the right eye using the same technique described above for WGA-HRP injection in monkey 1 . Four days later, $1 \mathrm{mg}$ of WGA-HRP was injected into the left eye. Again, $1 \mathrm{mg}$ of dexamethasone was injected in the retrobulbar space to reduce eye inflammation from the WGA-HRP.

Histological procedures. After allowing $9 \mathrm{~d}$ for $\left[{ }^{3} \mathrm{H}\right]$ proline transport and $5 \mathrm{~d}$ for WGA-HRP transport (except monkey 1, which received only WGA-HRP and $4 \mathrm{~d}$ for transport), the monkeys were given a lethal injection of $500 \mathrm{mg}$ of pentobarbital sodium into the peritoneal cavity. They were perfused through the left ventricle with 11 of normal saline followed by 11 of $2 \%$ paraformaldehyde. The lateral geniculate bodies and occipital lobes were placed immediately into $0.1 \mathrm{M}$ PBS. Visual cortex was dissected from the white matter of the occipital lobe, unfolded, flattened with gentle pressure $\left(\sim 8 \mathrm{gm} / \mathrm{cm}^{2}\right)$, and cryoprotected overnight with $30 \%$ sucrose. It was then frozen flat by placing the pial surface on a plastic-coated slide while pressing against the white matter with a bag of powdered dry ice (Horton, 1984). Sections were cut at $35 \mu \mathrm{m}$ on a freezing microtome. For monkey 1, alternating sections were mounted and processed for CO activity (Wong-Riley, 1979) or reacted free-floating to visualize WGA-HRP using tetramethylbenzidine (Mesulam, 1978). For monkeys 2, 3, and 4, every third section was coated for autoradiography with Kodak NTB2 emulsion, reacted for $\mathrm{CO}$, or processed free-floating for WGA-HRP. The lateral geniculate bodies were cut at $50 \mu \mathrm{m}$, and alternating sections were processed for either WGA-HRP or autoradiography. Selected sections of the cortex and the lateral geniculate body were counterstained for Nissl substance.

Image analysis. Single WGA-HRP sections were photographed under dark-field illumination through crossed polaroid filters with Plus-X-Pan film (Eastman Kodak, Rochester, NY). The film was developed with Microdol-X (Eastman Kodak) and scanned directly into a computer using a Microtek 35t ScanMaster (Redondo Beach, CA). Photoshop 3.0 (Adobe Systems) software was used to prepare photomontages from individual serial images. To montage a given cortical layer, a single section containing the largest portion of that layer was selected as the "base section." An adjacent section was then inspected, and the "lasso" tool was used to encircle any portion of the section containing the layer of interest. This area was rendered semitransparent to align it with the underlying base section by matching large blood vessels. The floating section fragment was then merged with the base section. This process was repeated with subsequent images until the montage was complete. The brightness and contrast of individual sections were adjusted to blend fragments evenly and to increase the visibility of columns. This procedure was equivalent to altering the exposure or contrast grade of photographic paper in the darkroom. Apart from these adjustments in brightness and contrast, the images were not retouched or adulterated in any way with the computer to erase seams between photomontage fragments or to enhance column patterns.

The cortical autoradiographs were developed with D-19 (Eastman Kodak) after an exposure of 10 weeks. Images were photographed in dark-field illumination using Technical Pan film (Eastman Kodak) and processed with Technidol (Eastman Kodak) developer. Negatives were then scanned into the computer and processed as described above for WGA-HRP images.

Sections stained for $\mathrm{CO}$ or Nissl substance were photographed using $4 \times 5$ inch Ektapan (Eastman Kodak) film, developed with HC110 (Eastman Kodak), and printed onto grade 4 Rapitone (Agfa) paper. Quantitative measurements of the autoradiographs, CO, and WGAHRP sections were made using Mocha software (Jandel Scientific, San Rafael, CA). 
Table 2. Measurements of squirrel monkey V1

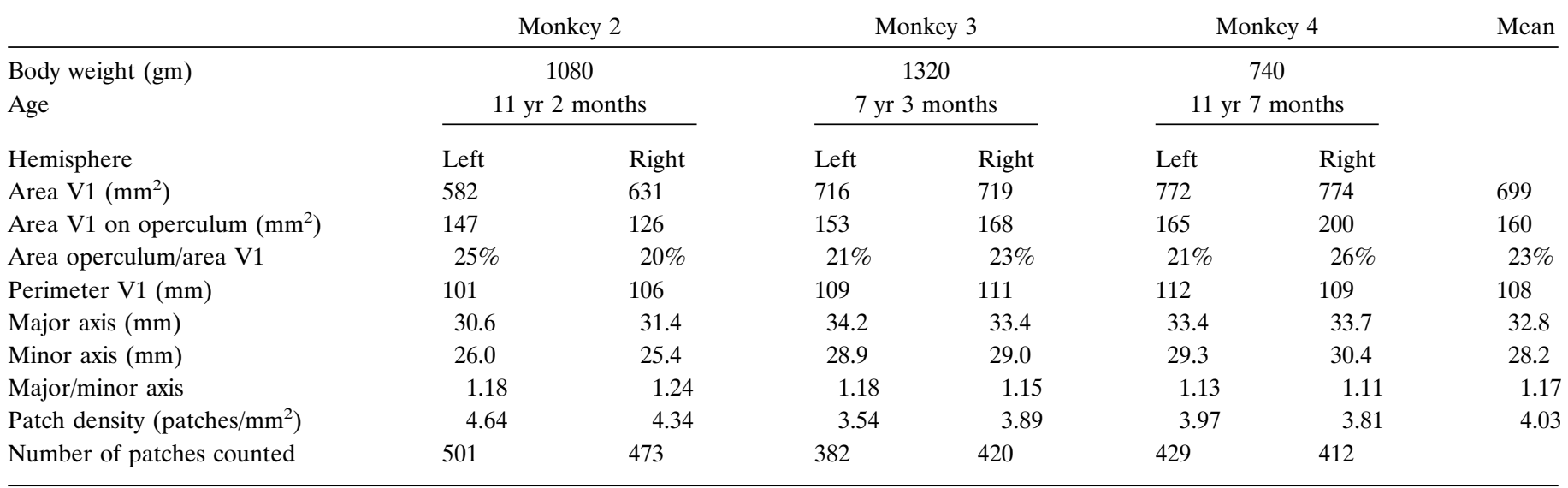

${ }^{a}$ Monkey 1 was an 18 month old, 900 gm male. The tissue tore during flat-mounting so no area measurements were included in this table.

\section{RESULTS}

\section{Columns in layer IVc}

The surface of striate cortex in the living squirrel monkey is covered by a dense vascular network, making it easy to see the V1/V2 boundary on the exposed cerebrum with the naked eye (Cowey, 1964). Even after perfusion, this boundary remains obvious because striate cortex is slightly darker than surrounding extrastriate cortex (Fig. 1). The exposed portion of striate cortex on the lateral convexity of the hemisphere is called the "operculum." This region, the only portion of squirrel monkey striate cortex mapped in detail, represents the central $3-4^{\circ}$ of the visual hemifield (Cowey, 1964). The remainder of striate cortex is situated along the medial face of the hemisphere and within the calcarine fissure. The task of unfolding and flattening striate cortex in a single piece is aided greatly by the visibility of the $\mathrm{V} 1 / \mathrm{V} 2$ border during dissection.

A portion of a single section from the flattened left striate cortex of monkey 1 processed for WGA-HRP is shown in Figure $2 A$. This region was located in the far periphery of $\mathrm{V} 1$, buried in the anterior end of the calcarine fissure. The bright WGA-HRP reaction product was not distributed in a uniform manner. Instead, it formed a complex mosaic of light and dark columns with

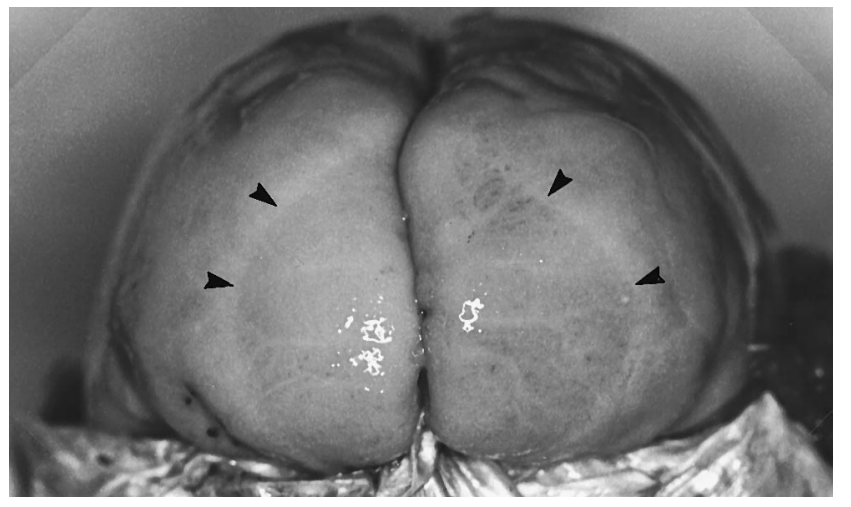

Figure 1. Brain of squirrel monkey 4 viewed from the rear after perfusion. The V1/V2 boundary (arrowheads) is visible to the naked eye because $\mathrm{V} 1$ is slightly darker. The portion of V1 exposed posteriorly on the brain surface is called the operculum (see shaded region in Fig. 3C). Most of V1 is hidden from view, located along the medial surface of the occipital lobe or folded within the calcarine fissure. indistinct borders. By later counterstaining for Nissl substance, we determined that these columns were located in layer IVc $\alpha$. A similar distribution of label was found in the right striate cortex. The pattern was reminiscent of the ocular dominance columns in the cat, which appear patchy (Shatz et al., 1977; Anderson et al., 1988) compared with the tidy "zebra stripes" of the macaque (LeVay et al., 1985). The columns in Figure $2 A$ were irregular and blurred, making quantitative measurements difficult. An estimate of the average column diameter was obtained by measuring the widths of 20 arbitrarily selected column pairs. The mean column diameter was $440 \mu \mathrm{m} /$ pair $( \pm 90 \mu \mathrm{m} \mathrm{SD})$.

In layer IVc $\beta$, the distribution of WGA-HRP label was dense and nearly homogeneous, rendering the pattern of columns seen in layer IV $\alpha$ almost invisible (not illustrated). Adjacent sections through layer IVc $\alpha$ and IVc $\beta$ stained for CO showed dark, uniform enzyme activity (not illustrated). There was nothing in the CO stain to explain the columns of WGA-HRP label discovered in layer IVc $\alpha$.

Figure $2 B$ shows distinct patches (also known as puffs or blobs) of $\mathrm{CO}$ activity in layers II,III from the same region of cortex (Hendrickson et al., 1981; Horton and Hubel, 1981; Horton, 1984). An adjacent section, cut $35 \mu \mathrm{m}$ deeper, revealed the distribution of WGA-HRP label from the right eye (Fig. 2C). There was a perfect match between each puff of WGA-HRP label and each CO patch, confirming previous studies (Livingstone and Hubel, 1982; Fitzpatrick et al., 1983; Weber et al., 1983; Horton, 1984; Itaya et al., 1984). In the macaque, the $\mathrm{CO}$ patches are organized into long rows, with each row fitting in register with an ocular dominance column in layer IVc (Horton and Hubel, 1981; Horton, 1984). After tracer injection into one eye, transneuronal label appears only in every other row of $\mathrm{CO}$ patches, overlaying the labeled set of ocular dominance columns (Horton and Hocking, 1996). In the squirrel monkey, on the other hand, every $\mathrm{CO}$ patch was labeled equally by injection of tracer into just one eye. This finding means that patches in the squirrel monkey get direct binocular geniculate input, whereas in the macaque this input is monocular.

The puffs of WGA-HRP label in layers II,III were similar in size to the gaps in WGA-HRP label visible in layer IV $\alpha$. To test the idea that the gaps in layer IV $\alpha$ might correspond to the puffs in layers II,III, we drew the labeled columns in Figure $2 A$ by eye. The puffs in Figure $2 C$ were outlined in a similar manner. The two patterns were then superimposed on the 

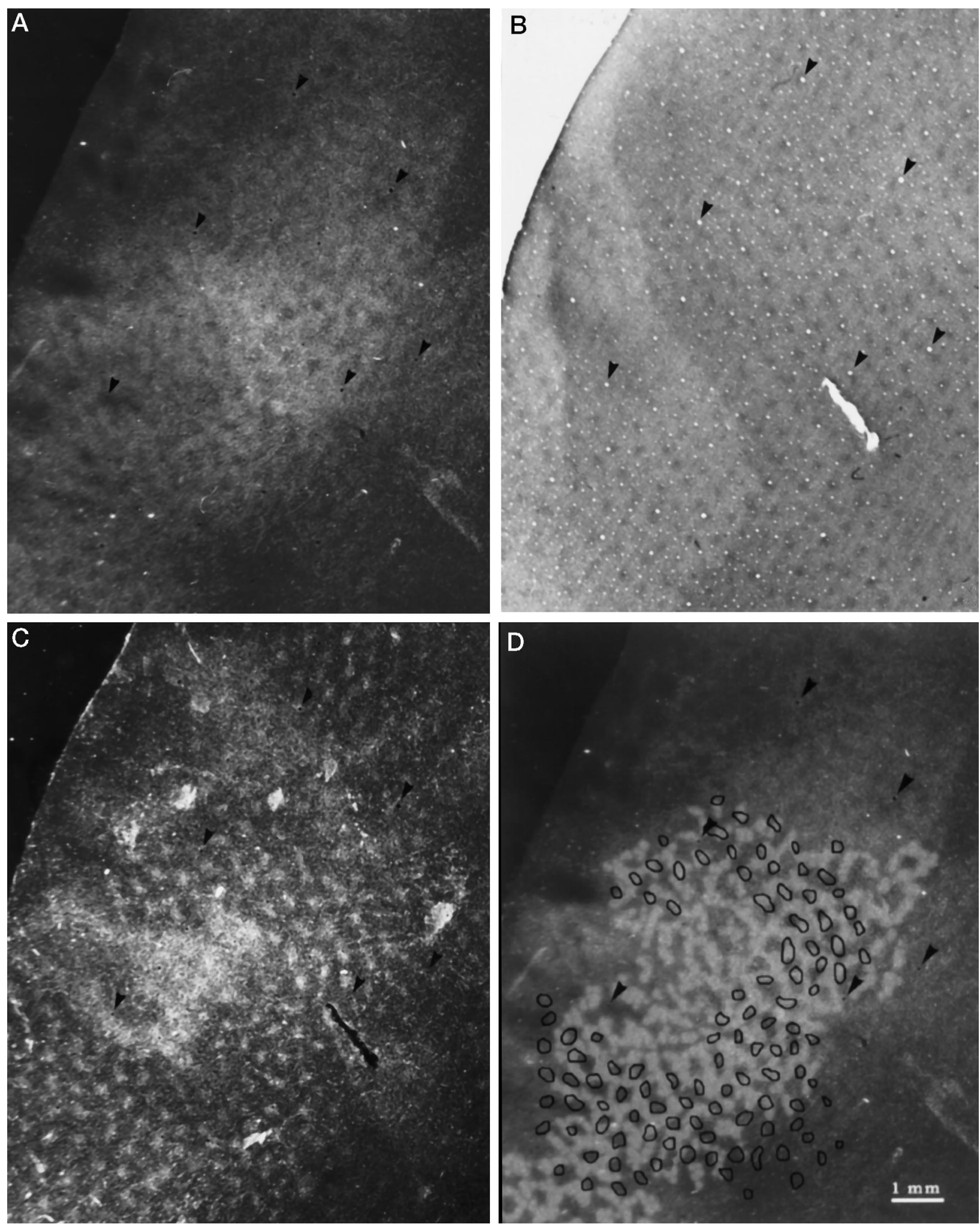

Figure 2. A, Section from the peripheral left striate cortex of monkey 1 through layer IVc $\alpha$ showing the distribution of WGA-HRP after injection into the right eye. The tracer is organized into a complex mosaic of columns, interrupted by unlabeled gaps. Arrowheads show key blood vessels used for section alignment in panels $A-D . B$, CO-stained section cut $210 \mu \mathrm{m}$ more superficially from the same block, showing the array of patches in layer III. $C$, Adjacent section cut $35 \mu \mathrm{m}$ deeper than $B$, showing distinct patches of WGA-HRP, except in the center where the label becomes more confluent as the section grazes the "honeycomb" in layer IVa. All the patches are labeled equally after tracer injection into just one eye, and each labeled patch superimposes on a CO patch in C. D, Comparison between the labeled columns in $A$, which have been reinforced in white, and the patches in $C$, which have been outlined in black. Overall, there is no consistent alignment between the columns and patches, although occasionally they coincide. The mean column width is 220 $\mu \mathrm{m}$, whereas the patches are spaced $\sim 500-700 \mu \mathrm{m}$ apart. 

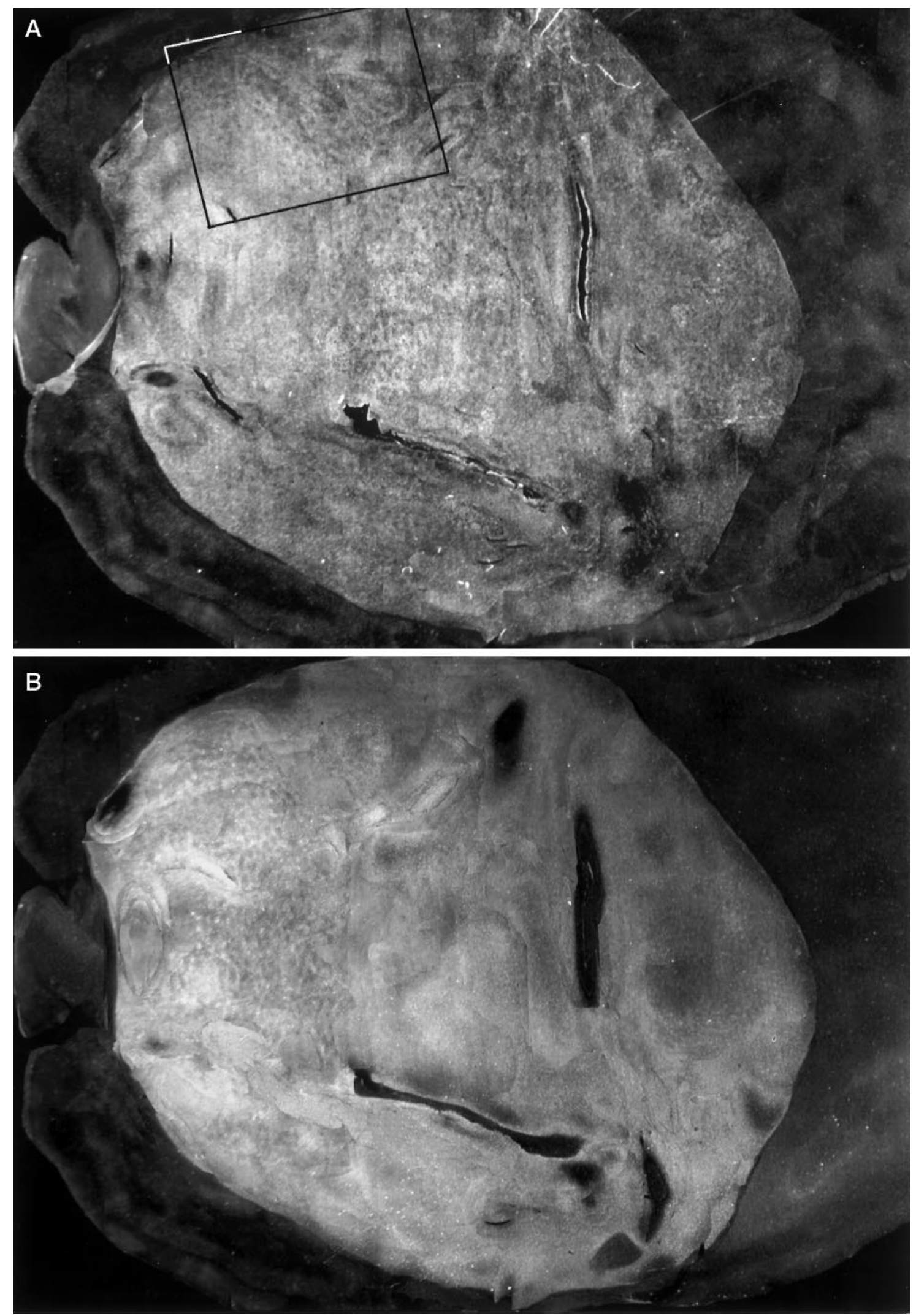

Figure 3. A, Montage of WGA-HRP label from the left eye in layer IVc $\alpha$ of the right cortex of monkey 4. Faint columns are visible throughout most of the montage. The rectangle delineates the portion of the flat-mount shown at higher power in Figure 4. $B$, Montage of autoradiographs through layer IVc $\alpha$ showing columns of $\left[{ }^{3} \mathrm{H}\right]$ proline label from the right eye. $C$, Sketch of the columns labeled in V1, prepared by combining the WGA-HRP data in $A$ and the proline data in $B$. The contrast of the columns in $B$ was reversed so that the black columns throughout the figure represent the ocular dominance columns of the right eye. They form an irregular array of short stripes and islands, with a mean diameter of $225 \mu \mathrm{m}$. The shaded area corresponds to the operculum, grossly visible in Figure 1, representing the central 3-4 ${ }^{\circ}$. Figure 3 continues. 


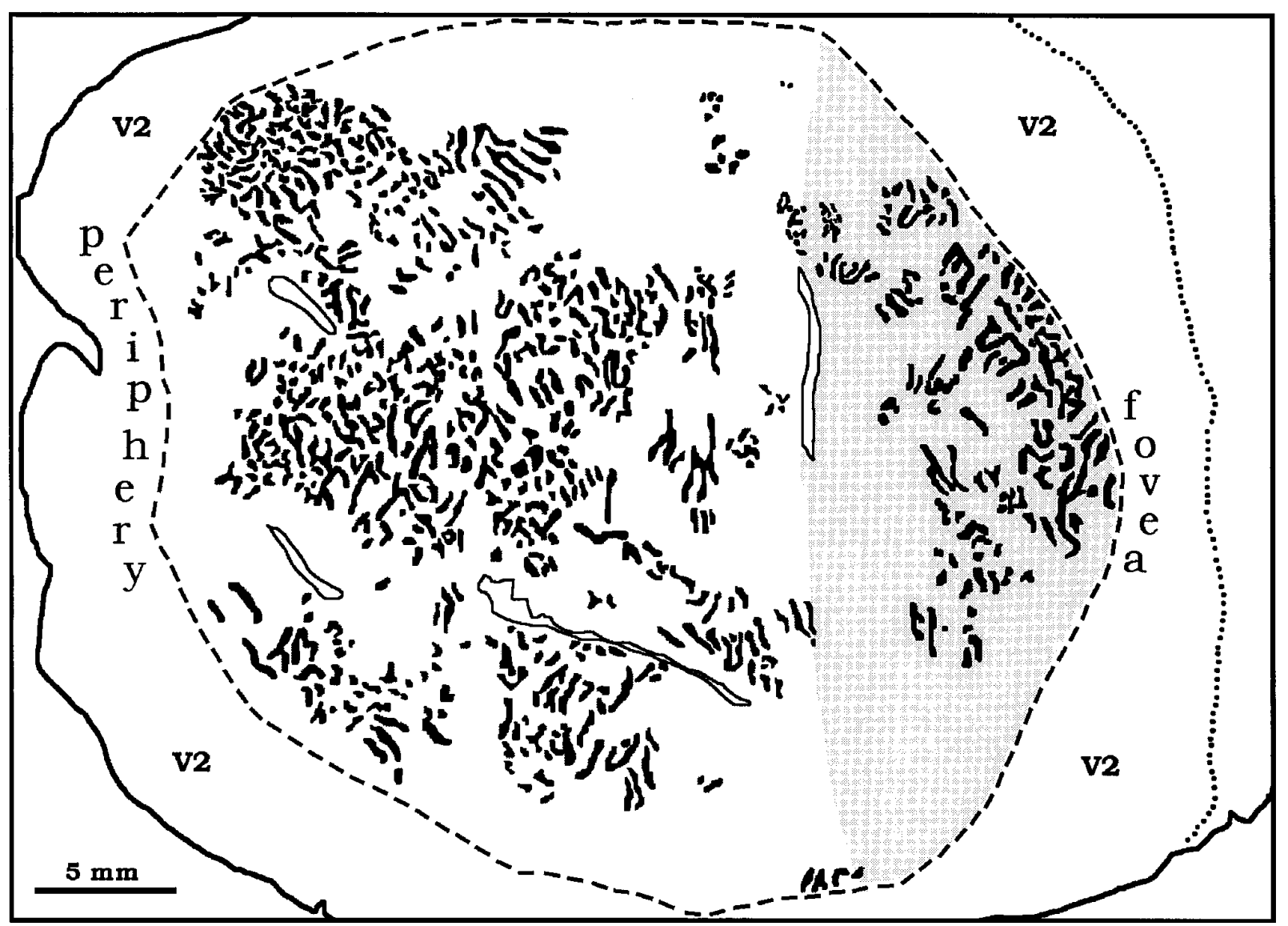

Figure 3 continued.

computer screen and aligned by matching prominent blood vessels (Fig. 2D). In some regions, the puffs of label in the upper layers seemed to fall into the unlabeled gaps in layer IVc $\alpha$. However, in other areas, the puffs of label in layers II,III coincided with the label in layer IVc $\alpha$, or straddled the border between labeled and unlabeled columns. Overall, we could detect no consistent relationship between the pattern of label in layer IVc $\alpha$ and the puffs of label corresponding to the $\mathrm{CO}$ patches.

\section{Double-label evidence for ocular dominance columns}

We next sought to clarify whether the columns of label shown in Figure $2 A$ truly represent ocular dominance columns. To qualify as ocular dominance columns, which are defined as alternating inputs in layer IVc, the unlabeled gaps must be supplied by the other eye. In a different scheme of cortical organization, one might imagine geniculate afferents serving each eye projecting to the same regions of layer IVc, leaving uninnervated gaps within a mosaic of intermingled binocular input. To distinguish between these two possibilities, a different transneuronal tracer was injected into each eye to double-label striate cortex.

Monkeys 2, 3, and 4 received $\left[{ }^{3} \mathrm{H}\right]$ proline in the right eye and WGA-HRP in the left eye. In all six hemispheres, the $\left[{ }^{3} \mathrm{H}\right]$ proline label showed columns in layer IV $\alpha$. The WGA-HRP label failed in monkey 3, yielding diffuse label and no columns in layer IVc. For this reason, comparison between WGA-HRP and $\left[{ }^{3} \mathrm{H}\right]$ proline was possible only in monkeys 2 and 4 . We illustrate monkey 4 , but the results we describe were confirmed in monkey 2 .
Figure $3 A$ shows a photomontage of WGA-HRP label in layer IVc $\alpha$ of the flat-mounted right cortex of monkey 4. The montage was constructed almost entirely from just three sections. In the squirrel monkey, layer IVc $\alpha$ receives input from the magnocellular laminae of the lateral geniculate body (Fitzpatrick et al., 1983; Weber et al., 1983). Looking closely, one can see an extensive mosaic of fine, irregular columns throughout most of the montage. The columns are difficult to appreciate because their contrast is low and their borders are indistinct. Layer IVc $\beta$, the parvo-receiving cortical layer, showed even less distinct columns. We could not find a break in the WGA-HRP label corresponding to the blind spot representation in layer IVc $\alpha$ or layer IVc $\beta$. In fact, we found no evidence for a label-free zone that might correspond to the blind spot in any animal with either proline or WGA-HRP. The same was true for the monocular crescent: no animal had a distinct zone at the anterior end of striate cortex with label from only the contralateral eye. We do not understand why these monocular landmarks were not seen.

Figure $3 B$ shows a montage of $\left[{ }^{3} \mathrm{H}\right]$ proline in layer IVc $\alpha$ from the same flat-mount. The label was organized into a pattern of indistinct columns, just like the WGA-HRP in adjacent sections. The columns were more visible in the anterior half of striate cortex, representing visual field beyond the central $10^{\circ}$. This effect resulted from several technical artifacts. The ocular dominance columns are known to label more crisply and strongly in peripheral cortex than central cortex after proline eye injection (LeVay et al., 1978). In addition, layer IVc $\alpha$ was only $\sim 80 \mu \mathrm{m}$ thick after 
fixation, flattening, and freezing of the cortex. As a result, cutting alternate tangential sections at $35 \mu \mathrm{m}$ left barely enough tissue to obtain a piece of layer IVc $\alpha$ for processing with each label: WGA-HRP, $\left[{ }^{3} \mathrm{H}\right]$ proline, and CO. For any local portion of the photomontage, the pattern of columns looked most distinct in either WGA-HRP or $\left[{ }^{3} \mathrm{H}\right]$ proline, depending on which labeled section happened to capture the heart of layer IVc $\alpha$. This is apparent when comparing Figure 3, $A$ and $B$. In areas where the columns were seen best with proline, they were less visible with WGA-HRP, and vice versa. The WGA-HRP and proline labels were coextensive, together yielding columns that could be sketched with reasonable accuracy throughout much of striate cortex (Fig. 3C). The columns formed an irregular lattice of short stripes and patches, looking nothing like mosaics reconstructed in the macaque and human. Their average periodicity, measured across 50 arbitrarily chosen sets of columns, was $450 \mu \mathrm{m} /$ pair $( \pm 50 \mu \mathrm{m} \mathrm{SD})$.

The montages in Figure 3, $A$ and $B$, could not be compared directly, because blood vessels required for aligning the montages were difficult to match at low power. Therefore, we analyzed local portions of single, adjacent WGA-HRP sections and autoradiographs at higher power. This allowed us to achieve reliable alignment of column patterns by matching constellations of prominent fiduciary blood vessels. An example is shown in Figure 4. The sections of WGA-HRP label (Fig. $4 A$ ) and $\left[{ }^{3} \mathrm{H}\right]$ proline label (Fig. $4 B)$ are from the region of the flat-mount enclosed by the box in Figure $3 A$. For each section, we drew the columns independently and then superimposed them using matching blood vessels as the sole criteria for alignment (Fig. $4 D$ ). The columns of proline and WGA-HRP dovetailed into an alternating pattern, indicating that they truly represent ocular dominance columns, serving the right eye and the left eye, respectively.

We drew the CO patches in a section through layer III (Fig. 4C) to test their relationship to the ocular dominance columns. The sketch of the patches was superimposed on the drawing of ocular dominance columns, again relying on blood vessels for alignment (Fig. 4D). There appeared to be no regular correlation between the $\mathrm{CO}$ patches and the ocular dominance columns, confirming the result illustrated in Figure $2 D$ for monkey 1.

\section{Scrambled parvocellular inputs in the lateral geniculate body}

The ocular dominance columns we found in the squirrel monkey were quite indistinct. Moreover, the columns were more blurred in layer IVc $\beta$ than in layer IVc $\alpha$, whereas the reverse is true in the macaque. We looked at the pattern of WGA-HRP and $\left[{ }^{3} \mathrm{H}\right]$ proline label in the lateral geniculate body to see whether excessive tracer spillover (LeVay et al., 1978) might account for these differences.

In Nissl sections, the two magnocellular laminae were separated by a narrow interlaminar fibrous zone (Fig. $5 A, B$ ). The $\left[{ }^{3} \mathrm{H}\right]$ proline label was clearly segregated into distinct laminae (Fig. $5 C, D$ ). The situation was different for the parvocellular laminae: in Nissl sections, they fused into a single dorsal cell mass without fibrous interlaminar zones to isolate left eye and right eye inputs (Le Gros Clark, 1941). Previous investigators have identified four distinct parvocellular laminae in squirrel monkeys by monocular visual deprivation or by tracer injection into one eye (Doty et al., 1966; Kaas et al., 1978; Fitzpatrick et al., 1983; Tigges et al., 1984). Although we could recognize segregated inputs to laminae 5 and 6 , the inputs to laminae 3 and 4 were scrambled. Throughout the region occupied by laminae 3 and 4 on each side, the $\left[{ }^{3} \mathrm{H}\right]$ proline label was distributed in a mosaic of small patches, separated by unlabeled gaps (Fig. 5C,D). Adjacent sections reacted for WGAHRP showed that the gaps were innervated by the other eye (not illustrated). The intermingling of projections was so extensive that laminae 3 and 4 hardly could be regarded as distinct laminae. The lack of fibrous interlaminar zones to separate the parvo laminae and the jumbling of inputs in laminae 3 and 4 probably explains why ocular dominance columns were nearly invisible in layer IVc $\beta$ (parvo input) compared with layer IVc $\alpha$ (magno input).

In late fetal life, intermingled retinal inputs segregate into distinct monocular laminae in the lateral geniculate body (Rakic, 1977) in a process not unlike the formation of ocular dominance columns in the cortex. What function do these laminae serve, and why are they so poorly defined in the squirrel monkey? These questions, often posed about the ocular dominance columns, are just as relevant for the laminae of the lateral geniculate body.

\section{Functional architecture of squirrel monkey striate cortex}

Flat-mounting the occipital lobe provided a first look at the overall shape of V1 in the squirrel monkey (Fig. 6). It appeared nearly circular, in striking contrast to the elliptical form seen in macaques, humans, and other primates with sharply defined ocular dominance columns oriented perpendicular to the V1/V2 border. To measure the major axis, we bisected V1 with a line drawn through the foveal representation where V2 becomes thinnest. The minor axis was defined as the broadest dimension perpendicular to the major axis. The mean ratio of major/minor axis was $1.17 / 1$. The equivalent ratio is $2.0-1.5 / 1$ in the macaque (Van Essen et al., 1984) and about 2/1 in the human (Horton and Hoyt, 1991).

The mean area of V1 in six hemispheres was $699 \mathrm{~mm}^{2}$, close to Cowey's original figure of $722 \mathrm{~mm}^{2}$ estimated from serial sections cut through seven specimens. In each flat-mount, there was a crease or gap in the cortical sheet along the hinge where it folds around onto the operculum (Fig. 1). This artifact enabled us to measure the operculum, which represents the central 3-4 ${ }^{\circ}$. It averaged $160 \mathrm{~mm}^{2}$, equivalent to $23 \%$ of the total striate surface area. In macaques and humans, the central 3-4 accounts for 35\% of V1 (Van Essen et al., 1984; Horton and Hoyt, 1991). This difference suggests that central vision is relatively less magnified in squirrel monkeys.

In a flat-mount of the right cortex of monkey 4, we counted 2,857 patches in V1 (Fig. 6A), less than half the total of 6000-9000 estimated for the macaque (Horton, 1984). The patches were visible in all cortical layers except IVc and formed an orderly array of rows oriented perpendicular to the V1/V2 border (Fig. 6B), just as in the macaque or human. These rows were spaced 500-700 $\mu \mathrm{m}$ apart. In the macaque, the density of patches depends on the location in V1 (Horton, 1984; Livingstone and Hubel, 1984). To measure the density of patches in different regions of squirrel monkey V1, we placed a grid of $3 \times$ $3 \mathrm{~mm}$ squares over each flat-mount and counted the patches within 12 widely separated sample boxes. The density of patches did not vary with location. The average patch density $\left(4.03 / \mathrm{mm}^{2}\right)$ (Table 2) was less than the patch density in the macaque operculum $\left(5.14 / \mathrm{mm}^{2}\right)$ (Horton, 1984).

\section{DISCUSSION}

In all eight hemispheres of four normal squirrel monkeys, we found columns in layer IVc after eye injection with a transneuronal tracer. In two animals, we successfully double-labeled these 

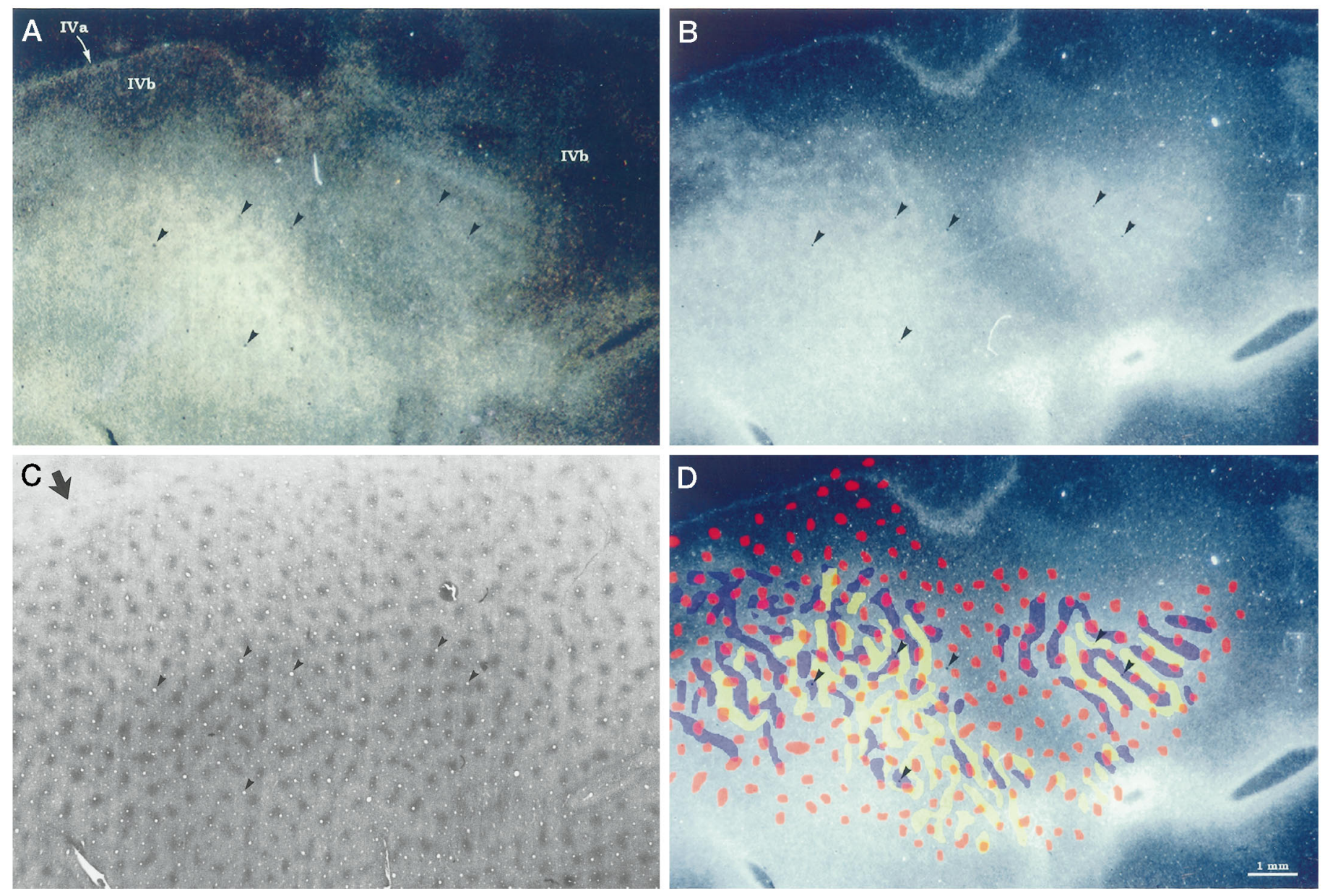

Figure 4. $A$, Single section outlined by the rectangle in Figure $3 A$ passing mostly through layer IVc $\alpha$ showing columns of yellow WGA-HRP reaction product from the left eye. At this magnification, the blood vessels used in each panel for section alignment are visible (arrowheads). B, Single autoradiograph from an adjacent section showing columns of $\left[{ }^{3} \mathrm{H}\right]$ proline label from the right eye. $C$, Single section cut $245 \mu \mathrm{m}$ more superficially from the same block showing the CO patches in layer III. A glimpse of the V1/V2 border is seen at the top left (arrow). $D$, Schematic diagram showing columns of WGA-HRP label $(A)$ in yellow and columns of $\left[{ }^{3} \mathrm{H}\right]$ proline $(B)$ in blue. The two patterns dovetail, indicating that they represent alternating inputs from the left and right eyes, respectively. The blobs drawn in brownish-orange represent the CO patches in $C$. We found no correspondence between patches and ocular dominance columns.

columns by putting $\left[{ }^{3} \mathrm{H}\right]$ proline into one eye and WGA-HRP into the other eye. Comparison of adjacent sections showed interdigitation of the two cortical labels, establishing that squirrel monkeys have ocular dominance columns. They were indistinct, indicating that ocular inputs vary widely in their degree of cortical segregation among primates, but their presence was unequivocal. Although the function of ocular dominance columns remains unknown, the notion that they are important for stereopsis is still a valid concept, albeit unproven.

In the first study of squirrel monkey after $\left[{ }^{3} \mathrm{H}\right]$ proline eye injection, Hubel et al. (1976) found "no hint of any columnar organization." This surprising result was confirmed by other investigators using the same methods (Tigges et al., 1977; Hendrickson et al., 1978; Rowe et al., 1978). However, in an abstract, Hubel and Wiesel (1978) later reported that "one can see some suggestion of mild periodic variations in density of label, especially in the upper part of layer IVc (IVc $\alpha$ )." Electrode recordings showed “a periodic fluctuation in dominance from one eye to the other at intervals of about $250 \mu \mathrm{m}$." Despite this report, Livingstone and Hubel (1982) subsequently observed that "in squirrel monkeys ocular dominance columns have not so far been revealed by anatomical methods" and Livingstone et al. (1995) stated, "the squirrel monkey differs from old-world macaques in that it lacks any anatomical evidence for ocular dominance columns." In view of the uncertainty reflected in the above-referenced sources, we felt that another anatomical study searching for ocular dominance columns in the squirrel monkey was warranted. Our present findings are in excellent agreement with Hubel and Wiesel (1978). It is worth mentioning that Fitzpatrick et al. (1983) saw patches of label in layer IVc $\beta$ after geniculate injection in a single squirrel monkey and suggested that they might be ocular dominance columns.

In the cat, Shatz et al. (1977) have noted crisper columns after eye injection in a strabismic animal. They suggested that elimination of binocular interactions by strabismus increased the segregation of geniculocortical afferents, making columns more visible in autoradiographs. Tigges et al. (1984) raised squirrel monkeys with early monocular eyelid suture and found in one animal that "a few irregularly spaced patches of higher grain density occurred deep in layer IVc." Again, disruption of binocular fusion might 

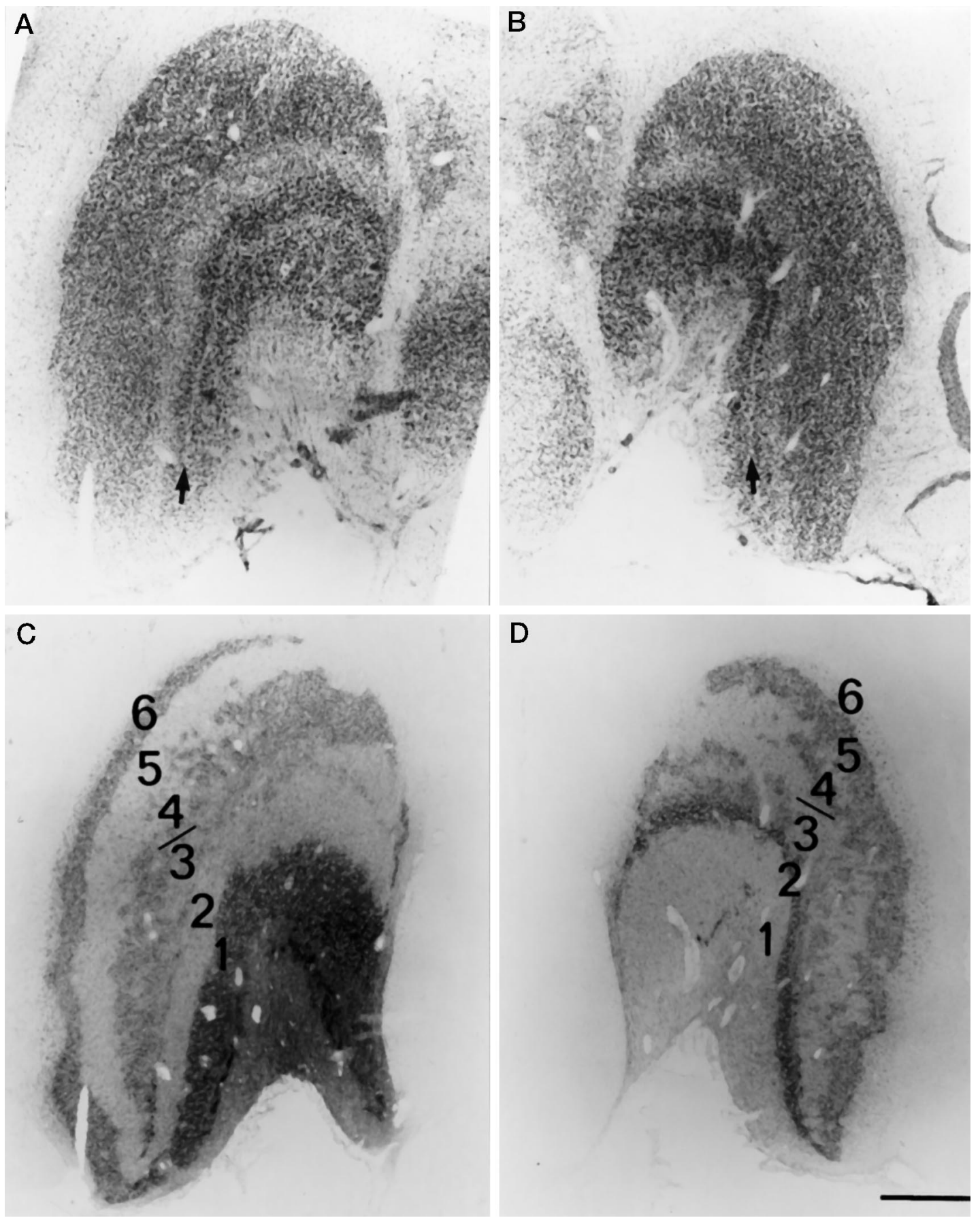

Figure 5. Nissl sections of the left $(A)$ and right $(B)$ lateral geniculate bodies showing a single fused dorsal parvocellular mass, without fibrous interlaminar zones to limit spillover of label. The two ventral magnocellular laminae are separated by a fibrous interlaminar zone (arrows). Autoradiographs of these sections are shown in $C$ and $D$. Laminae 3 and 4 on each side are comprised of an archipelago of labeled and unlabeled islands, partly merging these laminae and increasing the opportunity for label spillover. The autoradiographs were stripped of their emulsion and stained with cresyl violet to prepare the Nissl sections. Scale bar, $1 \mathrm{~mm}$.

have induced ocular dominance columns in layer IVc. More recently, Livingstone (1996) has shown ocular dominance columns in two of three squirrel monkeys raised with strabismus. A single control monkey showed no columns. In the normal squirrel monkey, she recorded from layer IVc and isolated nine monocular cells. From these findings, she concluded the following. (1) In normal squirrel monkeys, there is a "salt-and-pepper" segregation of inputs in layer IVc, but it occurs on too fine a scale to visualize with "the kinds of anatomical experiments previously used to reveal ocular dominance columns." (2) Strabismus coarsens the segregation of geniculocortical afferents by reducing correlated activity, thereby inducing the formation of ocular dominance columns. This phenomenon was predicted by Goodhill (1993) and first reported in strabismic cats by Löwel (1994). 

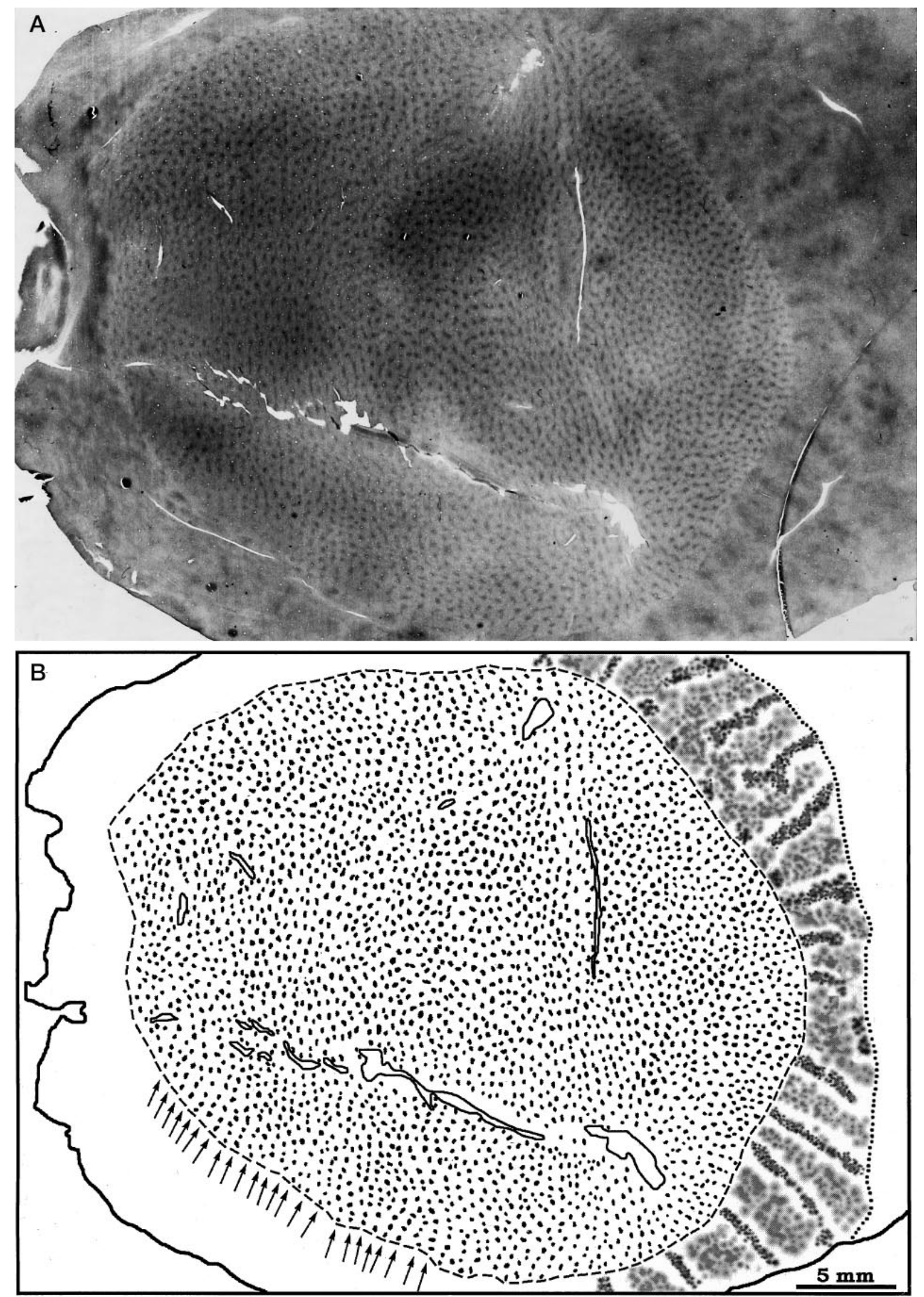

Figure 6. A, Single CO section from the right cortex of monkey 4, the same flat-mount illustrated in Figure 3, showing the patches in the upper layers. The CO stripes in V2 are also visible. $B$, Sketch of the patches in V1 and the stripes in V2. There are 2857 patches organized into rows, perpendicular to the V1/V2 border (arrows). The density of patches is uniform throughout V1. In V2, the thin stripes are darker than the thick stripes. 
Our present study shows that ocular dominance columns do exist in normal squirrel monkeys, contrary to Livingstone's first conclusion. With regard to her second conclusion, our findings appear to confirm her observation that strabismus increases the periodicity of ocular dominance columns. We measured $450 \mu \mathrm{m} /$ column pair in normal squirrel monkeys, whereas Livingstone found $1300-1600 \mu \mathrm{m} /$ column pair in a strabismic squirrel monkey. However, in the same report, Livingstone (1996) found no change in the periodicity of ocular dominance columns in owl monkeys raised with strabismus. Moreover, a recent study denies that any change occurs in the spacing of ocular dominance in strabismic cats (Jones et al., 1996).

There are two intertwined, but separate issues raised by these strabismus experiments. The first is whether strabismus enhances the segregation of geniculocortical afferents, thereby sharpening the borders of ocular dominance columns in layer IVc. This notion seems likely, and indeed, ocular dominance columns were first discovered in strabismic cats, not normal cats, because their ocular dominance columns were accentuated by strabismus (Hubel and Wiesel, 1965). It has been difficult to show the anatomical correlate of this effect because the sharpness and quality of tracer labeling varies from animal to animal, even in normals. For example, in monkey 3 we saw no columns in V1 with WGA-HRP. From this result, we might have concluded that monkey 3 lacked ocular dominance columns, except for the fact that they were nicely labeled by $\left[{ }^{3} \mathrm{H}\right]$ proline in alternate sections. The success of transneuronal labeling is influenced by many technical factors, such as the quality of perfusion, amount and activity of label, avidity of tracer uptake, spillover, background labeling, and so on. More animals need to be studied to overcome the intrinsic variability in column labeling that occurs from experiment to experiment before we can be sure that columns are sharper in strabismic animals.

The second issue is whether strabismus alters the fundamental periodicity of ocular dominance columns. In macaques this seems unlikely, because ocular dominance columns form in utero, before visual experience can play a role (Horton and Hocking, 1996). In the squirrel monkey, comparing our data with Livingstone's, strabismus appears to increase the periodicity of the ocular dominance columns. However, one must bear in mind that the periodicity of ocular dominance columns varies enormously in normal animals. Their average width ranges by a factor of almost 2 from one normal macaque to another (Hocking and Horton, 1996). Nevertheless, Livingstone's strabismic squirrel monkeys have more than twice the column width of our normal squirrel monkeys. This difference strongly suggests a real effect, but it should be confirmed in more animals given the confounding factors cited above.

The columns in squirrel monkeys were only $\sim 225 \mu \mathrm{m}$ in width, the narrowest ocular dominance columns found in any animal to date. They were organized in a fractured, irregular mosaic, without any consistent relationship to the V1/V2 border. In primates with an elliptical V1, such as humans, macaques, capuchins, and talapoins, the ocular dominance columns are arrayed in stripes perpendicular to the V1/V2 border (Horton and Hedley-Whyte, 1984; LeVay et al., 1985; Rosa et al., 1988; Florence and Kaas, 1992). This arrangement may minimize anisotropies created by the necessity of representing the visual field twice in layer IVc, once for each eye (Connolly and Van Essen, 1984; LeVay et al., 1985; Jones et al., 1991). The seemingly random, patchy arrangement of ocular dominance columns in the squirrel monkey is consistent with a rounder shape to $\mathrm{V} 1$ and suggests a more isotropic cortical map (Sakitt, 1982).

In every primate studied so far, rows of patches in the upper layers have been in register with ocular dominance columns in layer IVc. In the cat, the relationship between the CO staining in the upper layers and the ocular dominance columns is unclear (Dyck and Cynader, 1993; Murphy et al., 1995; Boyd and Matsubara, 1996). In the squirrel monkey, we found no correspondence between the patches and the ocular dominance columns. The patches were lined up in regular rows $\sim 500-700 \mu \mathrm{m}$ apart, perpendicular to the V1/V2 border. The periodicity of the ocular dominance columns was much finer $(\sim 450 \mu \mathrm{m} /$ pair $)$, and they followed an entirely different pattern. Occasionally, a patch fell in step with an ocular dominance column, as one would expect by coincidence, but overall the two systems were unrelated. Previously, we have suggested that the patches provide the fundamental organizing pattern for the columnar architecture of striate cortex, on which ocular dominance columns become engrafted late in fetal development (Horton, 1984). It is remarkable that ocular dominance columns are divorced from $\mathrm{CO}$ patches in squirrel monkeys, because this relationship seems so inviolable in other primates.

It is natural to inquire about the visual properties of squirrel monkeys, searching to explain why they differ so much from macaques and humans. As alluded to earlier, squirrel monkeys have good stereoscopic depth perception (Livingstone et al., 1995). They also have excellent color vision, although the males are dichromats (Jacobs and Neitz, 1987). Most studies have shown a comparable visual acuity for squirrel monkeys and humans (Woodburne, 1965; Ordy and Samorajski, 1968; Cavonius and Robbins, 1973). The spatial vision of squirrel monkeys and humans is extremely similar, as measured by plotting contrast sensitivity at different spatial frequencies (Merigan, 1976). These psychophysical studies indicate that basic visual performance in squirrel monkeys rivals that of humans. This is puzzling when one considers that squirrel monkeys have only a fraction of the striate surface area, weakly defined ocular dominance columns, and a system of $\mathrm{CO}$ patches that bears no relationship to ocular dominance. Evidently, the functional architecture of striate cortex tolerates wide variation in design, without any compromise in function. This fact has made it hard to deduce how each feature contributes to visual processing.

\section{REFERENCES}

Anderson PA, Olavarria J, Van Sluyters RC (1988) The overall pattern of ocular dominance bands in cat visual cortex. J Neurosci 8:2183-2200.

Boyd J, Matsubara J (1996) Laminar and columnar patterns of geniculocortical projections in the cat: relationship to cytochrome oxidase. J Comp Neurol 365:659-682.

Casagrande VA, Harting JK (1975) Transneuronal transport of tritiated fucose and proline in the visual pathways of tree shrew Tupaia glis. Brain Res 96:367-372.

Cavonius C, Robbins D (1973) Relationships between luminance and visual acuity in the rhesus monkey. J Physiol (Lond) 232:239-246.

Connolly M, Van Essen DC (1984) The representation of the visual field in parvicellular and magnocellular layers of the lateral geniculate nucleus in the macaque monkey. J Comp Neurol 226:544-564.

Cowey A (1964) Projection of the retina on to striate and prestriate cortex in the squirrel monkey, Saimiri sciureus. J Neurophysiol 127:366-393.

DeBruyn EJ, Casagrande VA (1981) Demonstration of ocular dominance columns in a new world primate by means of monocular deprivation. Brain Res 207:453-458.

Diamond IT, Conley M, Itoh K, Fitzpatrick D (1985) Laminar organization of geniculocortical projections in Galago senegalensis and Aotus trivirgatus. J Comp Neurol 242:584-610. 
Doty RW, Glickstein M, Calvin WH (1966) Lamination of the lateral geniculate nucleus in the squirrel monkey, Saimiri scirueus. J Comp Neurol 127:335-340.

Dräger UC (1974) Autoradiography of tritiated proline and fucose transported transneuronally from the eye to the visual cortex in pigmented and albino mice. Brain Res 82:284-292.

Dyck RH, Cynader MS (1993) An interdigitated columnar mosaic of cytochrome oxidase, zinc, and neurotransmitter-related molecules in cat and monkey visual cortex. Proc Natl Acad Sci USA 90:9066-9069.

Fitzpatrick D, Itoh K, Diamond IT (1983) The laminar organization of the lateral geniculate body and the striate cortex in the squirrel monkey (Saimiri sciureus). J Neurosci 3:673-702.

Florence SL, Kaas JH (1992) Ocular dominance columns in area 17 of old world macaque and talapoin monkeys: complete reconstructions and quantitative analyses. Vis Neurosci 8:449-462.

Florence SL, Conley M, Casagrande VA (1986) Ocular dominance columns and retinal projections in new world spider monkeys (Ateles ater). J Comp Neurol 243:234-248.

Glendenning KK, Kofron EA, Diamond IT (1976) Laminar organization of projections of the lateral geniculate nucleus to the striate cortex in Galago. Brain Res 105:538-546.

Goodhill GJ (1993) Topography and ocular dominance: a model exploring positive correlations. Biol Cybern 69:109-118.

Hendrickson AE, Tigges M (1985) Enucleation demonstrates ocular dominance columns in old world macaque but not in new world squirrel monkey visual cortex. Brain Res 333:340-344.

Hendrickson AE, Wilson JR (1979) A difference in $\left[{ }^{14} \mathrm{C}\right]$ deoxyglucose autoradiographic patterns in striate cortex between macaca and saimiri monkeys following monocular stimulation. Brain Res 170:353-358.

Hendrickson AE, Wilson JR, Ogren MP (1978) The neuroanatomical organization of pathways between the dorsal lateral geniculate nucleus and visual cortex in old world and new world primates. J Comp Neurol 182:123-136.

Hendrickson AE, Hunt SP, Wu J-Y (1981) Immunocytochemical localization of glutamic acid decarboxylase in monkey striate cortex. Nature 292:605-607.

Hess DT, Edwards MA (1987) Anatomical demonstration of ocular segregation in the retinogeniculocortical pathway of the new world capuchin monkey (Cebus apella). J Comp Neurol 264:409-420.

Hitchcock PF, Hickey TL (1980) Ocular dominance columns: evidence for their presence in humans. Brain Res 182:176-179.

Hocking DR, Horton JC (1996) Pronounced intrinsic variability of ocular dominance column periodicity in normal macaque monkeys. Soc Neurosci Abstr 22:682.9.

Holländer H, Hälbig W (1980) Topography of retinal representation in the rabbit cortex: an experimental study using transneuronal and retrograde tracing techniques. J Comp Neurol 193:701-710.

Horton JC (1984) Cytochrome oxidase patches: a new cytoarchitectonic feature of monkey visual cortex. Philos Trans R Soc Lond Biol 304:199-253.

Horton JC, Hedley-Whyte ET (1984) Mapping of cytochrome oxidase patches and ocular dominance columns in human visual cortex. Philos Trans R Soc Lond Biol 304:255-272.

Horton JC, Hocking DR (1996) An adult-like pattern of ocular dominance columns in striate cortex of newborn monkeys prior to visual experience. J Neurosci 16:1791-1807.

Horton JC, Hoyt WF (1991) The representation of the visual field in human striate cortex. Arch Ophthalmol 109:816-824.

Horton JC, Hubel DH (1981) Regular patchy distribution of cytochrome oxidase staining in primary visual cortex of macaque monkey. Nature 292:762-764.

Hubel DH (1975) An autoradiographic study of the retino-cortical projections in the tree shrew (Tupaia glis). Brain Res 96:41-50.

Hubel DH, Wiesel TN (1965) Binocular interaction in striate cortex of kittens reared with artificial squint. J Neurophysiol 28:1041-1059.

Hubel DH, Wiesel TN (1969) Anatomical demonstration of columns in the monkey striate cortex. Nature 221:747-750.

Hubel DH, Wiesel TN (1977) Functional architecture of macaque monkey visual cortex. Proc R Soc Lond [Biol] 198:1-59.

Hubel DH, Wiesel TN (1978) Distribution of inputs from the two eyes to striate cortex of squirrel monkeys. Soc Neurosci Abstr 4:632.

Hubel DH, Wiesel TN, LeVay S (1976) Functional architecture of area 17 in normal and monocularly deprived macaque monkeys. Cold Spring Harb Symp Quant Biol 40:581-589.
Humphrey AL, Hendrickson AE (1983) Background and stimulusinduced patterns of high metabolic activity in the visual cortex (area 17) of the squirrel and macaque monkey. J Neurosci 3:345-358.

Itaya SK, Itaya PW, Van Hoesen GW (1984) Intracortical termination of the retino-geniculo-striate pathway studied with transsynaptic tracer (wheat germ agglutinin-horseradish peroxidase) and cytochrome oxidase staining in the macaque monkey. Brain Res 304:303-310.

Jacobs GH, Neitz J (1987) Inheritance of color vision in a New World monkey (Saimiri sciureus). Proc Natl Acad Sci USA 84:2545-2549.

Jones DG, Van Sluyters RC, Murphy KM (1991) A computational model for the overall pattern of ocular dominance. J Neurosci 11:3794-3808.

Jones DG, Murphy KM, Van Sluyters RC (1996) Spacing of ocular dominance columns is not changed by monocular deprivation or strabismus. Invest Ophthalmol Vis Sci 37:1964.

Kaas JH, Huerta MF, Weber JT, Harting JK (1978) Patterns of retinal terminations and laminar organization of the lateral geniculate nucleus of primates. J Comp Neurol 182:517-554.

Law MI, Zahs KR, Stryker MP (1988) Organization of primary visual cortex (area 17) in the ferret. J Comp Neurol 278:157-180.

Le Gros Clark WE (1941) The lateral geniculate body in the platyrrhine monkeys. J Anat 76:131-140.

LeVay S, Nelson SB (1991) Columnar organization of the visual cortex. In: The neurological basis of visual function vision and visual dysfunction (Cronly-Dillon J, Leventhal A, eds), pp 266-315. Boca Raton: CRC.

LeVay S, Stryker MP, Shatz CJ (1978) Ocular dominance columns and their development in layer IV of the cat's visual cortex: a quantitative study. J Comp Neurol 179:223-244.

LeVay S, Connolly M, Houde J, Van Essen DC (1985) The complete pattern of ocular dominance stripes in the striate cortex and visual field of the macaque monkey. J Neurosci 5:486-501.

Livingstone MS (1996) Ocular dominance columns in new world monkeys. J Neurosci 16:2086-2096.

Livingstone MS, Hubel DH (1982) Thalamic inputs to cytochrome oxidase-rich regions in monkey visual cortex. Proc Natl Acad Sci USA 79:6098-6101.

Livingstone MS, Hubel DH (1984) Anatomy and physiology of a color system in the primate visual cortex. J Neurosci 4:309-356.

Livingstone MS, Nori S, Freeman DC, Hubel DH (1995) Stereopsis and binocularity in the squirrel monkey. Vision Res 35:345-354.

Löwel S (1994) Ocular dominance column development: strabismus changes the spacing of adjacent columns in cat visual cortex. J Neurosci 14:7451-7468.

McConnell SK, LeVay S (1986) Anatomical organization of the visual system of the mink, Mustela vison. J Comp Neurol 250:109-132.

Merigan WH (1976) The contrast sensitivity of the squirrel monkey (Saimiri sciureus). Vision Res 16:375-379.

Mesulam M-M (1978) Tetramethyl benzidine for horseradish peroxidase neurohistochemistry: a non-carcinogenic blue reaction-product with superior sensitivity for visualizing neural afferents and efferents. J Histochem Cytochem 26:106-117.

Murphy KM, Jones DG, Van Sluyters RC (1995) Cytochrome-oxidase blobs in cat primary visual cortex. J Neurosci 15:4196-4208.

Olavarria J, Van Sluyters RC (1985) Unfolding and flattening the cortex of gyrencephalic brains. J Neurosci Methods 15:191-202.

Ordy J, Samorajski T (1968) Visual acuity and ERG-CFF in relation to the morphologic organization of the retina among diurnal and nocturnal primates. Vision Res 8:1205-1225.

Pettigrew JD, Ramachandran VS, Bravo H (1984) Some neural connections subserving binocular vision in ungulates. Brain Behav Evol 24:65-93.

Price DJ (1985) Patterns of cytochrome oxidase activity in areas 17, 18 and 19 of the visual cortex of cats and kittens. Exp Brain Res 58:125-133.

Rakic P (1977) Prenatal development of the visual system in rhesus monkey. Philos Trans R Soc Lond Biol 278:245-260.

Rosa M, Gatass R, Fiorani Jr M (1988) Complete pattern of ocular dominance stripes in V1 of a new world monkey, Cebus apella. Exp Brain Res 72:645-648.

Rowe MH, Benevento LA, Rezak M (1978) Some observations on the patterns of segregated geniculate inputs to the visual cortex in new world primates: an autoradiographic study. Brain Res 159:371-378.

Sakitt B (1982) Why the cortical magnification factor in rhesus can not be isotropic. Vision Res 22:417-421.

Sanderson KJ, Haight JR, Pearson LJ (1980) Transneuronal transport of tritiated fucose and proline in the visual pathways of the brushtailed possum, Trichosurus vulpecula. Neurosci Lett 20:243-248. 
Shatz CJ, Lindström S, Wiesel TN (1977) The distribution of afferents representing the right and left eyes in the cat's visual cortex. Brain Res 131:103-116.

Spatz WB (1989) Loss of ocular dominance columns with maturity in the monkey, Callithrix jacchus. Brain Res 488:376-380.

Tigges J, Tigges M (1979) Ocular dominance columns in the striate cortex of chimpanzee (Pan troglodytes). Brain Res 166:386-390.

Tigges J, Tigges M, Perachio AA (1977) Complementary laminar terminations of afferents to area 17 originating in area 18 and in the lateral geniculate nucleus in squirrel monkey. J Comp Neurol 176:87-100.

Tigges M, Hendrickson AE, Tigges J (1984) Anatomical consequences of long-term monocular eyelid closure on lateral geniculate nucleus and striate cortex in squirrel monkey. J Comp Neurol 227:1-13.

Tootell RBH, Silverman MS (1985) Two methods for flat-mounting cortical tissue. J Neurosci Methods 15:177-190.
Van Essen D, Newsome W, Maunsell J (1984) The visual field representation in striate cortex of the macaque monkey: asymmetries, anisotropies, and individual variability. Vision Res 24:429-448.

Weber JT, Casagrande VA, Harting JK (1977) Transneuronal transport of $\left[{ }^{3} \mathrm{H}\right]$ proline within the visual system of the grey squirrel. Brain Res 129:346-352.

Weber JT, Huerta MF, Kaas JH, Harting JK (1983) The projections of the lateral geniculate nucleus of the squirrel monkey: studies of the interlaminar zones and the S layers. J Comp Neurol 213:135-145.

Wong-Riley M (1979) Changes in the visual system of monocularly sutured or enucleated kittens demonstrable with cytochrome oxidase histochemistry. Brain Res 171:11-28.

Woodburne L (1965) Visual acuity of Saimiri sciureus. Psychon Sci 3:307-308. 